\title{
PROPOSTA PARA DIRETRIZES DE GESTÃO AMBIENTAL PARA ATIVIDADE HOTELEIRA NO BRASIL
}

\section{PROPOSAL FOR ENVIRONMENTAL MANAGEMENT GUIDELINES FOR HOTEL ACTIVITY IN BRAZIL}

\author{
Marcos Antônio Bezerra Sereno1; Osvaldo Luiz Gonçalves Quelhas²; Sérgio Luiz Braga França 3; \\ Marcelo Jasmim Meiriño ${ }^{4}$; \\ ${ }^{1}$ Universidade Federal Fluminense - UFF - Niterói - RJ - Brasil \\ marcos.sereno@uol.com.br \\ ${ }^{2}$ Universidade Federal Fluminense - UFF - Niterói - RJ - Brasil \\ quelhas@latec.uff.br \\ ${ }^{3}$ Universidade Federal Fluminense - UFF - Niterói - RJ - Brasil \\ sfranca@latec.uff.br \\ ${ }^{4}$ Universidade Federal Fluminense - UFF - Niterói - RJ - Brasil \\ marcelo@latec.uff.br
}

\begin{abstract}
Resumo
Este artigo contextualiza as atividades relacionadas ao turismo "sustentável", tendo como foco as definições da literatura acerca da Indústria Hoteleira e do Desenvolvimento Sustentável, relacionadas ao aspecto ambiental. O método de pesquisa aplicado é o dedutivo. Trata-se de uma pesquisa aplicada, quanto à natureza exploratória e aos objetivos, e teórico-conceitual, quanto ao método. Realiza-se uma análise bibliométrica, a fim de identificar a produção acadêmica que relaciona atividades de hotelaria e a gestão ambiental. $O$ artigo identifica o que foi produzido, publicado e gerado de conhecimento pela comunidade científica em relação ao tema, além de analisar suas principais tendências. Para isso, foi construída uma árvore de palavras-chave, com o intuito de pesquisar publicações. Foi possível notar um aumento recente das publicações sobre o tema e identificar que a utilização de sistema de gestão ambiental, em atividade hoteleira, colabora para a eficácia da gestão e atua como fator de fomento da competitividade.
\end{abstract}

Palavras-chave: Sistemas de gestão ambiental (SGA); indústria hoteleira; desenvolvimento sustentável.

\section{Introdução}

O turismo pode ser uma opção ao desenvolvimento das comunidades e das pessoas. No entanto, se faz necessário um planejamento rigoroso, contando com a participação da comunidade envolvida, para que possa ser bem-sucedido (RUSCHMANN, 1997).

A Organização Mundial do Turismo (OMT) considera que, atualmente, o turismo é a atividade econômica que mais cresce, e até 2020, cerca de 1,5 bilhões de pessoas viajarão a cada 
ano pelo mundo. Este número é quase o dobro dos atuais 900 milhões de turistas que mobilizam US\$ 860 bilhões.

De acordo com dados do Ministério de Turismo (MTur), os desembarques domésticos e internacionais, a entrada de turistas estrangeiros no Brasil e a receita cambial do turismo deverão bater recordes nos próximos anos. Seguem dados comparativos entre os últimos anos, apresentados pela Diretoria de Estudos e Pesquisa:

- Em 2011, 79 milhões de desembarques de voos nacionais, acima dos 68,25 milhões de 2010.

- Em 2011, 9 milhões de desembarques de voos internacionais, acima dos 7,9 milhões de 2010.

Cabe destacar que os princípios da sustentabilidade vêm ocupando lugar de destaque entre as diretrizes estabelecidas pelo Plano Nacional de Turismo (PNT).

A investigação limitou-se à gestão ambiental fomentada no segmento turístico específico da hotelaria dentro de um contexto de turismo sustentável. Tem-se, portanto, a consciência da escassez de estudos sobre outros impactos causados ao meio ambiente pelo turismo na região e de que cada um deles em específico mereceria uma pesquisa mais aprofundada.

Desta maneira, não foram verificados ou analisados os segmentos do comércio, ou outros serviços prestados no turismo, nem mesmo as organizações informais e cruzeiros marítimos, apesar de suas representatividades. Ressalta-se que se fazem necessários estudos posteriores, com acompanhamentos in loco, para analisar a evolução do setor como um todo e o estágio em que se encontra o ciclo de vida deste destino turístico.

Com efeito, é possível argumentar que, na gestão profissional do turismo, o mesmo requer, como paradigma básico, a maximização da qualidade nos serviços prestados aliada às boas práticas de sustentabilidade.

Na perspectiva do turismo sustentável, deve-se ater para o fato de que um novo perfil de turista (pós-turista) mais consciente e mais ético é necessário para uma atividade turística mais responsável, uma vez que é fundamental a interação respeitando-se as culturas locais. Para (NASCIMENTO e SILVA, 2009), o pós-turista busca qualidade diversificada nos serviços do local visitado, valoriza a cultura com a sua complexidade e particularidade peculiares. Este turista possui valores que definem que as paisagens naturais necessitam ser preservadas, compreendendo que faz parte de um ambiente que oferecerá, às populações envolvidas, a qualidade de vida, com boas expectativas para gerações futuras. A estrutura dessa nova demanda ambiental e cultural acrescenta um conjunto de características à gestão do negócio da hotelaria. 
Diante do contexto apresentado, cabe definir as questões da pesquisa: Quais os desafios que a hotelaria tende a enfrentar para tornar-se ambientalmente responsável? Como deverão essas empresas se comportar doravante, para que se mantenham no mercado e atendam a uma demanda crescente de turistas cada vez mais exigentes, do ponto de vista ambiental e de serviços especializados? Quais as diretrizes de gestão para a hotelaria ambiental brasileira?

Para responder à formulação da situação-problema, o objetivo desta pesquisa é a análise da relação entre a indústria hoteleira e o desenvolvimento sustentável no Brasil e no mundo, tendo como objetivo principal definir diretrizes de implantação da gestão ambiental em hotelaria.

\section{Material e métodos}

A revisão de literatura apresenta conceitos e definições sobre as tendências do turismo sustentável no Brasil e o no mundo, a necessidade de envolver outros atores das partes interessadas e a importância do uso de ferramentas adequadas e viáveis para a sustentabilidade dos empreendimentos hoteleiros.

\subsection{Tendências na gestão e práticas de sustentabilidade no setor turístico}

Com a tendência de crescimento do turismo no Brasil, a expectativa dos empresários é muito positiva, principalmente em função dos dois maiores eventos esportivos do mundo: a Copa do Mundo em 2014 e a Olimpíada de 2016. O momento atual é oportuno para disseminar e refletir sobre a prática da sustentabilidade no setor turístico. Nos últimos anos, pôde-se constatar uma crescente preocupação internacional com estabelecimentos hoteleiros e a difusão de sistemas de gestão associados a certificações de qualidade e ambiental que tenham validade e reconhecimento global.

A adesão das empresas turísticas nacionais à implantação de sistemas de gestão ainda é inicial. No entanto, o segmento hoteleiro, entre outros segmentos turísticos, já percebe a necessidade de traçar estratégias competitivas para se manter no mercado.

Segundo dados da Associação Brasileira da Indústria de Hotéis (ABIH), representante oficial dos Meios de Hospedagem do Brasil e uma das mais antigas entidades do trade turístico nacional, o Parque Hoteleiro Nacional possui aproximadamente 25 mil meios de hospedagem e, deste universo, 18 mil são hotéis e pousadas, ou seja, aproximadamente $70 \%$ da hotelaria nacional é composta de empreendimentos de pequeno porte. 
Gráfico 1 - Distribuição dos meios de hospedagem por porte

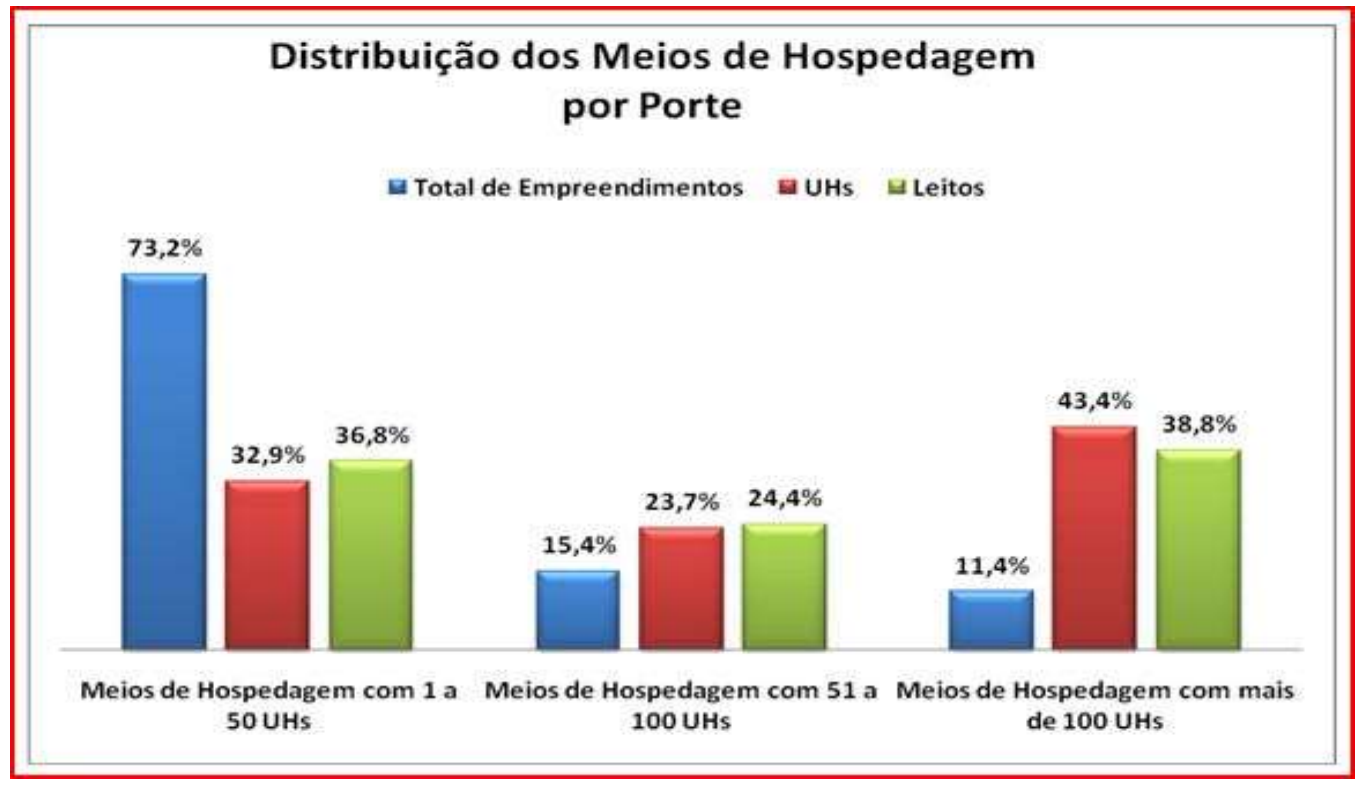

Fonte: ABIH - NACIONAL/2011

Analisando o Gráfico 1, se observa que: 73,2\% dos meios de hospedagem no país possuem até 50 UHs, representando 32,9\% da oferta nacional de UHs e 36,8\% de leitos. A maior concentração de UHs $(43,4 \%)$ é notada entre os empreendimentos hoteleiros de maior porte (com mais de $101 \mathrm{UHs}$ ). No estrato intermediário, a oferta de leitos corresponde a 24,4\% do total.

Considerando os dados acima apresentados e diante da sonhada sustentabilidade nas pequenas empresas do setor turístico, Swarbrooke (2000) afirma que o Turismo Sustentável deve ser debatido com base no conceito amplo do Desenvolvimento Sustentável (DS).

O turismo sustentável não está relacionado apenas à proteção ao meio ambiente; mas também está ligado à viabilidade econômica em longo prazo e à justiça social. O progresso, em direção às formas mais sustentáveis de turismo, dependerá muito mais das atividades da indústria do turismo e das atitudes do turista do que de ações de órgãos do setor público. (SWARBROOKE, 2000, p. VII-VIII, v. 1).

Este conceito evidencia que, para a sustentabilidade ser colocada em prática, é necessário o compartilhamento de deveres e de responsabilidade, cabendo a cada um dos envolvidos no sistema turístico uma parcela do exercício de atuação, não apenas aguardando as resoluções por parte do setor público. 


\subsubsection{Responsabilidades compartilhadas dos envolvidos no desenvolvimento do turismo Sistêmico}

A premissa de uma responsabilidade compartilhada é defendida por Krippendorf (2001), em sua obra "Sociologia do Turismo", onde o mesmo formula um irrecusável convite à responsabilidade individual que habita a consciência de cada um de nós, turistas em potencial.

Por sua vez, Sachs (1996) afirma que o desenvolvimento sustentável deve ser socialmente desejável, economicamente viável e ecologicamente prudente. Esta opinião é corroborada por Swarbrooke (2000), ao defender que o conceito de sustentabilidade engloba o meio ambiente, as pessoas e os sistemas econômicos, sendo também acolhida por Quelhas e Alledi (2006), quando afiançam que a sustentabilidade prega o uso responsável dos fatores sociais, ambientais e econômicos. Os dois últimos autores asseveram não ser por acaso que a palavra "responsável" surge na essência do movimento sustentável.

Acrescentam ainda os mesmos autores que:

Tudo o que se faz ou planeja para a responsabilidade social corporativa tem um destino preciso: a sustentabilidade dos negócios. A gestão das organizações ganha contornos cada vez mais sistêmicos, exigindo criatividade e multiplicidade de habilidades para garantir a sobrevivência. A gestão da qualidade, a gestão ambiental e a gestão da segurança do trabalho têm agora a companhia de gestão da ética, da transparência e da responsabilidade social (QUELHAS; ALLEDI. 2006. p. 223).

Atualmente, o turismo, enquanto atividade econômica se encontra em franca expansão e é capaz de mobilizar um enorme contingente de pessoas através do mundo. Além dos efeitos positivos sobre os destinos turísticos, pode também provocar impactos nos campos econômico, cultural, social e ambiental, apontando para a necessidade de estudos que embasem o seu planejamento e gestão dentro dos princípios da sustentabilidade, visando ao desenvolvimento local. Não se pode deixar de considerar, nesta análise, seu principal ator, o turista, que, quando consciente das suas "boas práticas", pode minimizar em muito os impactos causados ao meio ambiente e multiplicar os benefícios gerados por essa atividade. Dessa forma, justifica-se que se é bom para o turista também tem que ser bom para a comunidade local, pois um não existe sem o outro.

Na visão de Panosso Netto (2005), o fenômeno turístico constitui, hoje, importante meio de distribuição e geração de renda e é justamente esse o principal ponto focado pelos estudiosos de maneira geral. Em inúmeros textos, os benefícios sociais do turismo são esquecidos, originando, assim, uma visão fragmentada e superficial desse fenômeno, que necessita de uma interpretação minuciosa, fugindo dos textos acadêmicos reducionistas que simplesmente abordam uma ou duas de suas facetas (PANOSSO NETTO, 2005, p.19). 
O fato é que o turismo é amplo, complexo e multifacetado e são necessárias diferentes abordagens para estudar esse campo. Cada uma delas deve estar adaptada a uma tarefa ou objetivo diferente, como se pode observar na Figura 1 a seguir. No entendimento da abordagem sistêmica, para estudar turismo, seria necessária uma abordagem de sistemas. Os autores Goeldner; Ritchie e Mcintosh (2002) compreendem que:

Um sistema é um conjunto de grupos inter-relacionados, coordenados para formar um todo unificado e organizado, alcançando um conjunto de objetivos. Ele integra as outras abordagens em um método abrangente, lidando tanto com as questões macro como com as questões micro. Pode-se examinar o ambiente competitivo de uma empresa turística, seu mercado, seus resultados, seus vínculos com outras instituições, o consumidor e a interação da empresa com ele. Além disso, um sistema pode assumir o ponto de vista macro e examinar toda a estrutura turística de um país, estado ou área e como ela opera internamente, relacionando-se com outros sistemas, como o legal, o político, o econômico e o social. (GOELDNER, RITCHIE, MCINTOSH, 2002, p. 30).

Figura 1 - Fenômeno turístico: componentes do turismo e do gerenciamento turístico.

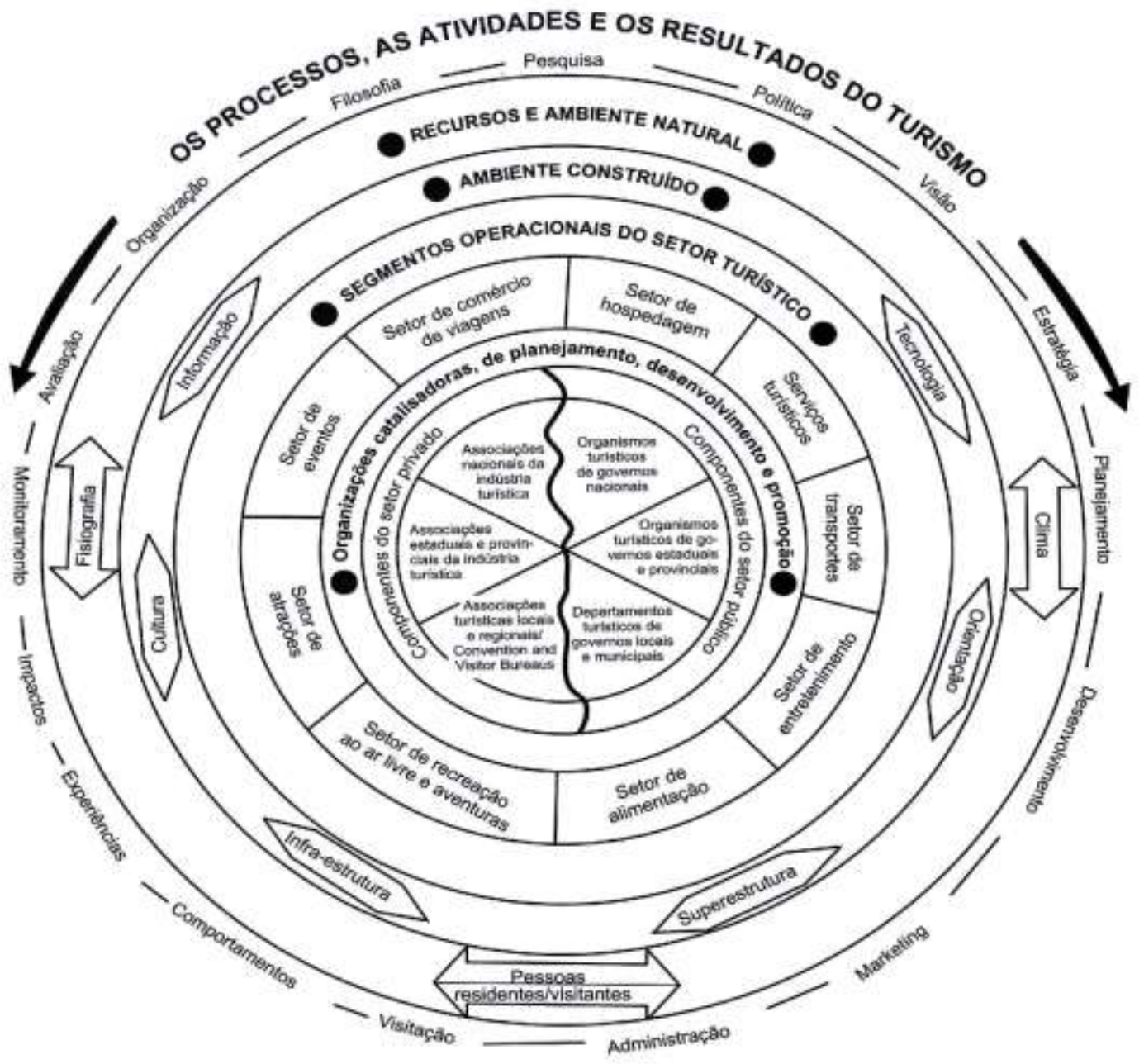

Fonte: Goeldner; Ritchie; Mcintosh (2002, p. 32). 
Com a abordagem de estruturar "soluções inovadoras em sua essência", abrem-se possibilidades para o debate sobre a real participação de cada ator envolvido na sustentabilidade do turismo, dos componentes do mesmo e do gerenciamento turístico dessa atividade.

Neste estudo, dá-se ênfase à ação particular do gestor que atua na indústria hoteleira, no cenário sistêmico do turismo, que tem um conjunto de grupos inter-relacionados com o objetivo de apresentar mais sustentação ao desenvolvimento de um determinado local ou região. Aqui também se enquadra a responsabilidade individual no comprometimento de cada stakeholder desse sistema turístico.

\subsubsection{Turismo sustentável e partes interessadas}

Para Swarbrooke (2000), são muitas as pessoas interessadas no campo do turismo sustentável, onde o planejamento do turismo passa pelo reconhecimento dos atores-chave dessa atividade e de suas respectivas responsabilidades. $\mathrm{O}$ autor enfatiza que, com uma rede complexa de interessados, não é simples definir o significado de turismo sustentável e como alcançá-lo.

Figura 2 - Turismo Sustentável - Partes interessadas

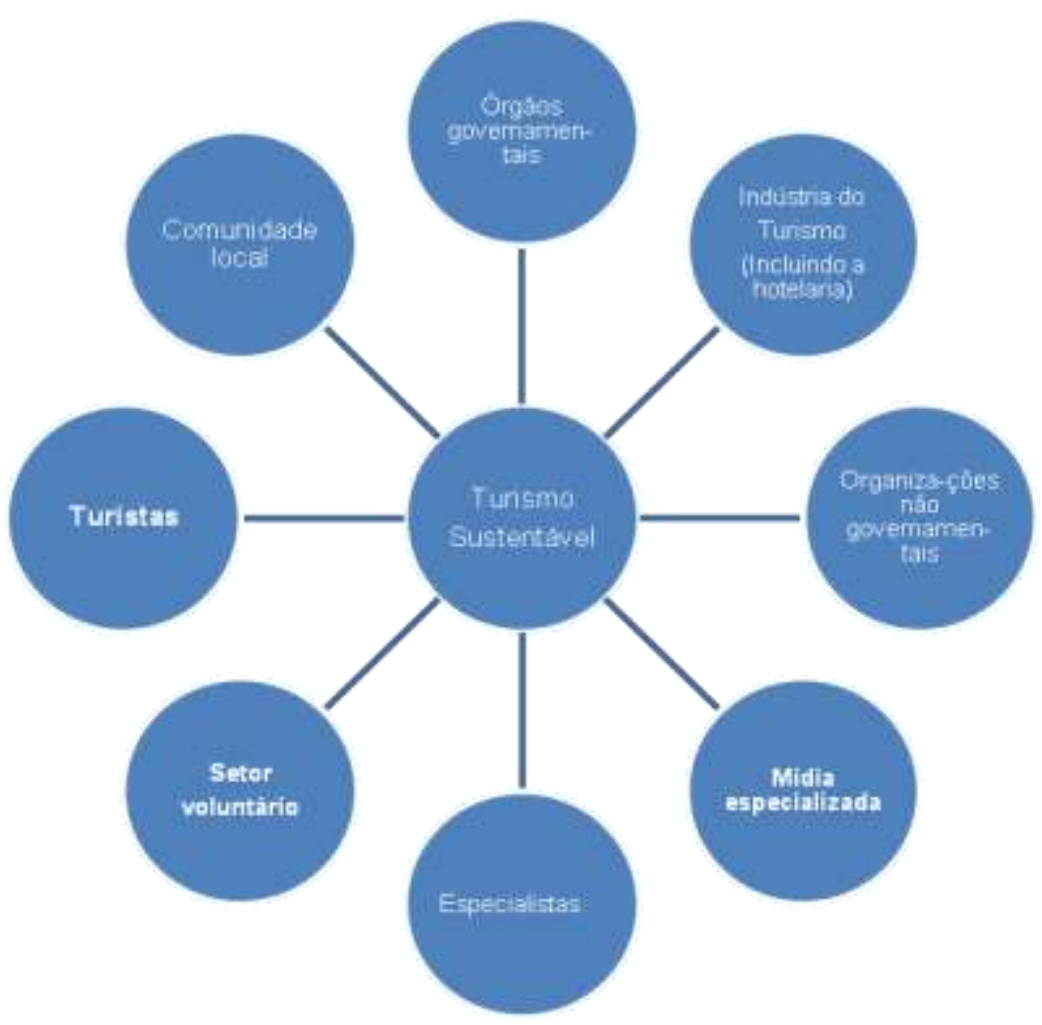

Fonte: Adaptado de Swarbrooke (2000, p. 24) 


\subsubsection{Práticas ambientais em uso na hotelaria}

A implantação de um Sistema de Gestão Ambiental (SGA) é uma etapa para a gestão sustentável na hotelaria. Sua implementação implica melhorar o desempenho ambiental das empresas, tendo como base a redução de desperdícios de água, fazendo seu uso de maneira racional, ou a utilização de fontes de energia alternativa e matéria-prima. Tais práticas também podem propiciar economia para o estabelecimento e, assim, todos os atores envolvidos no turismo podem colaborar e participar.

A discussão do assunto é cada vez mais necessária e importante, visto que, na atualidade, este requisito passa a ser indispensável para os empreendimentos que desejam se manter e/ou atingir um mercado internacional competitivo.

Nesta pesquisa, se buscou conhecer quais os motivos, limites e perspectivas que levam o empresário de um empreendimento hoteleiro a demandar um "selo verde" ou outras certificações disponíveis no mercado, que na realidade são de caráter voluntário.

A certificação, nos serviços de hotelaria, vem sendo bastante difundida, especialmente por dois motivos: porque as discussões sobre os ambientes estão bastante avançadas e aos poucos a sociedade, os clientes estão se tornando cada vez mais conscientes e acabam cobrando alternativas mais viáveis e menos impactantes ao espaço onde o empreendimento está inserido (MORAES, 2009, p. 7).

Ao se levar em consideração os motivos apresentados e que os consumidores estão se tornando mais exigentes, observa-se, atualmente, que os turistas estão procurando hospedagem que incorporam os princípios da responsabilidade ambiental. A preocupação com a natureza, que antes era um diferencial, passou a ser pré-requisito, possibilitando reduzir custos, manter e conquistar novos clientes, melhorar o desempenho em competitividade empresarial (SCHENINI, LEMOS, SILVA; 2005).

\subsection{Método de pesquisa}

Para a realização desta pesquisa, primeiramente foi apresentado o contexto em que se localiza o problema, justificando-se a importância do tema. Em seguida, definiu-se o objetivo geral da pesquisa, sendo realizada uma revisão de literatura baseada nos principais conceitos relacionados ao turismo sustentável no Brasil.

$\mathrm{Na}$ revisão de literatura, foram analisados os conceitos sobre o tema, concluindo-se que, apesar de diferentes, contêm fundamentos semelhantes, o que proporciona um entendimento mais claro sobre as potencialidades e barreiras na implantação de práticas sustentáveis na indústria hoteleira. 
A fundamentação teórica e o objetivo geral da pesquisa orientaram na definição das palavras-chave, que foram escolhidas com base nos termos mais relevantes e presentes tanto nas obras dos autores mais consagrados sobre o assunto, quanto no contexto global atual em que se encontra a difusão do tema. A definição das palavras-chave teve como objetivo a realização de uma pesquisa bibliográfica eficiente, na medida em que filtrou somente as publicações diretamente relacionadas ao tema.

Por fim, a pesquisa bibliométrica permitiu o apontamento da evolução das publicações, as principais bases de dados relacionadas ao assunto e as principais referências utilizadas pelos pesquisadores, bem como o estabelecimento de conclusões acerca do panorama atual e das tendências em relação ao tema.

O método científico utilizado nesta pesquisa é o dedutivo, que para Gill e Johnson (2002), é o método de abordagem que implica o desenvolvimento de uma estrutura conceitual e teórica. Os autores Turrioni e Mello (2011) complementam que a abordagem dedutiva tem o propósito de explicar o conteúdo das premissas. Pode-se dizer que os argumentos dedutivos ou estão corretos ou incorretos, não havendo graduações intermediárias.

Entende-se que o método dedutivo é o mais adequado para esta pesquisa, uma vez que o objetivo do estudo é propor um modelo conceitual de gestão da sustentabilidade focado no setor de hotelaria.

De acordo com as classificações das pesquisas mencionadas por Turrioni e Mello (2011), existem várias formas de classificar uma pesquisa. O presente estudo pode ser assim caracterizado:

- Quanto à natureza: aplicada.

- Quanto aos objetivos: exploratória.

- Quanto ao método: teórico-conceitual.

Para Turrioni e Mello (2011), a pesquisa aplicada caracteriza-se por seu interesse prático, ou seja, que os resultados sejam aplicados ou utilizados imediatamente na solução de problemas que ocorrem na realidade. Com base nesta definição, compreende-se que a pesquisa caracteriza-se como de natureza aplicada, uma vez que tem como objetivo propor um modelo de gestão da sustentabilidade que oriente as organizações no segmento da hotelaria. Para Gil (1996, p. 45), o objetivo da pesquisa exploratória é "proporcionar maior familiaridade com o problema, com vistas a torná-lo mais explícito ou construir hipóteses".

Nakano (2010, p. 65) define o método teórico-conceitual como "discussões conceituais a partir da literatura, revisões bibliográficas”. Berto e Nakano (2000) acrescentam que são modelagens conceituais, baseadas na percepção e experiências do autor. Face ao objetivo proposto 
desta pesquisa, considerou-se o método teórico/conceitual o mais adequado para o seu desenvolvimento.

Os resultados gerados foram baseados nos seguintes passos utilizados na elaboração da pesquisa bibliométrica.

\subsection{Definição das palavras-chave}

Com base em publicações científicas relevantes na área de Turismo Sustentável as palavraschave foram definidas a partir dos termos mais citados. As palavras-chave também foram traduzidas para a língua inglesa, com o objetivo de obter resultados nacionais e internacionais.

\subsection{Levantamento das publicações relevantes}

Após a definição das palavras-chave, iniciou-se a busca dos artigos relevantes, utilizando a lógica booleana com os conectivos "E", "OU” e "AND NOT” nas combinações das palavras-chave. De forma a obter uma fonte fidedigna, procurou-se limitar-se às publicações da base dos periódicos CAPES. Primeiramente, foram levantados todos os artigos publicados sobre o tema e observou-se que o primeiro artigo foi publicado em 1930. Em seguida, o estudo bibliográfico enfatizou as publicações de 2006 a 2012, buscando obter conclusões atualizadas sobre a realidade do tema.

\subsection{Revisão da amostra de publicações}

Com o auxílio dos mecanismos de busca disponíveis na Internet, foi possível refinar a pesquisa excluindo publicações que não possuíam nomes de autores e anos de publicação, publicações duplicadas, bem como publicações que possuíam as palavras-chave enquadradas, mas não obrigatoriamente relevantes ao tema em questão.

\subsection{Tratamento dos dados}

Após o filtro das publicações relevantes e completas, para fins estatísticos, foram efetuadas apurações, tais como: número de publicações por ano, principais bancos de dados, temas relacionados às palavras-chave e às publicações mais relevantes a partir de 2006 até 2012. Estas apurações foram necessárias para a geração de gráficos e análises estatísticas.

\subsection{Resultados e Conclusões}

De posse dos dados, foi possível extrair resultados e conclusões referentes à pesquisa bibliométrica e aos artigos científicos mais relevantes sobre o tema, publicados nos bancos de dados citados na pesquisa. 


\section{Resultado e discussão}

Este estudo bibliométrico teve como objetivo analisar os artigos relacionados com o tema proposto, no intuito de permitir melhor entendimento das áreas de interesse. A pesquisa foi realizada com base nas principais bases de dados disponíveis no Portal de Periódicos CAPES.

\subsection{Pesquisa com as palavras-chave (em português)}

Inicialmente foi realizada a pesquisa utilizando separadamente as seguintes palavras-chave: Sistemas de Gestão Ambiental, Indústria Hoteleira e Desenvolvimento Sustentável.

- Para a palavra "Sistema de Gestão Ambiental", foram identificados 19 registros, mas nenhum deles relacionado ao tema da pesquisa.

- Para a palavra "Indústria Hoteleira", foram identificados 4 registros, sendo um artigo relacionado ao tema da pesquisa.

- Para a palavra "Desenvolvimento Sustentável, foram identificados 157 registros de diversas áreas".

Gráfico 2 - Assuntos relacionados com a palavra-chave "Desenvolvimento Sustentável"

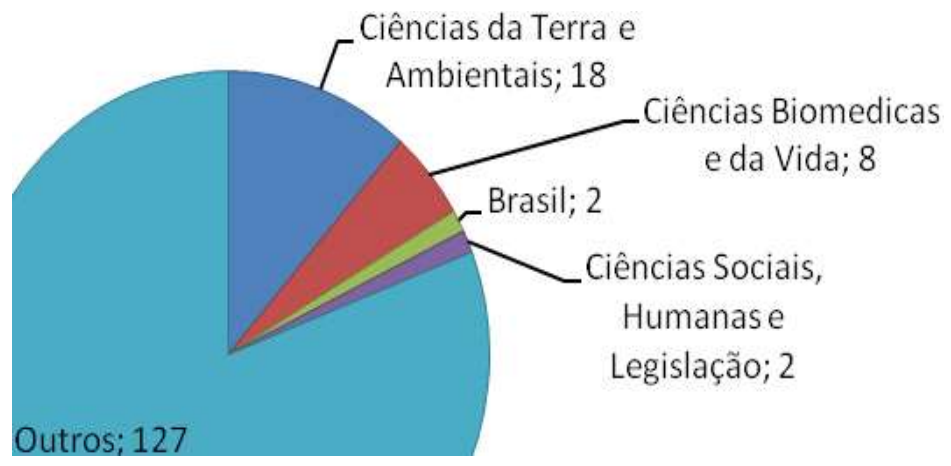

Fonte: Os autores

Neste caso, verifica-se, no Gráfico 2, que a palavra-chave em questão está relacionada a 127 assuntos distintos, uma vez que dentro de "Outro(a)" há apenas um registro em cada um dos assuntos agrupados neste item.

Conforme o resultado apresentado, a principal área-alvo é Ciências da Terra e Ambientais. Em segundo plano, percebe-se a presença da área Ciências Biomédicas e da Vida. Destaca-se o grande número de áreas com apenas uma (01) publicação, o que representa a amplitude e a complexidade do tema Desenvolvimento Sustentável. Esta situação motiva a necessidade de realizar novas buscas combinando as palavras-chave, duas a duas. 


\subsection{Pesquisa com as palavras-chave combinadas duas a duas (em português)}

- Para a combinação "Desenvolvimento Sustentável" e "Indústria Hoteleira", foram identificados 09 registros, mas nenhum deles relacionado ao tema da pesquisa.

- Para a combinação "Desenvolvimento Sustentável” e "Sistema de Gestão Ambiental”, foram identificados 11 registros, e novamente nenhum deles relacionado ao tema da pesquisa.

- Para a combinação "Sistema de Gestão Ambiental” e "Indústria Hoteleira", não foi encontrado nenhum registro.

\subsection{Pesquisa com as palavras-chave separadas (em inglês)}

Dando sequência ao estudo bibliométrico, foram realizadas buscas com as palavras-chave em inglês, separadamente: Environmental Management Systems (EMS) (Sistema de Gestão Ambiental), Hotel Industry (Indústria Hoteleira) e Sustainable Development (Desenvolvimento Sustentável).

- Para a palavra Environmental Management Systems foram identificados 264 registros.

De modo a analisar a distribuição de publicações relacionadas às palavras-chave selecionadas ao longo do tempo, foi gerado um gráfico que mostra a evolução do número de publicações realizadas nos últimos.

Gráfico 3 - Quantidade de registros por ano de publicação relacionada com a palavra-chave "EMS"

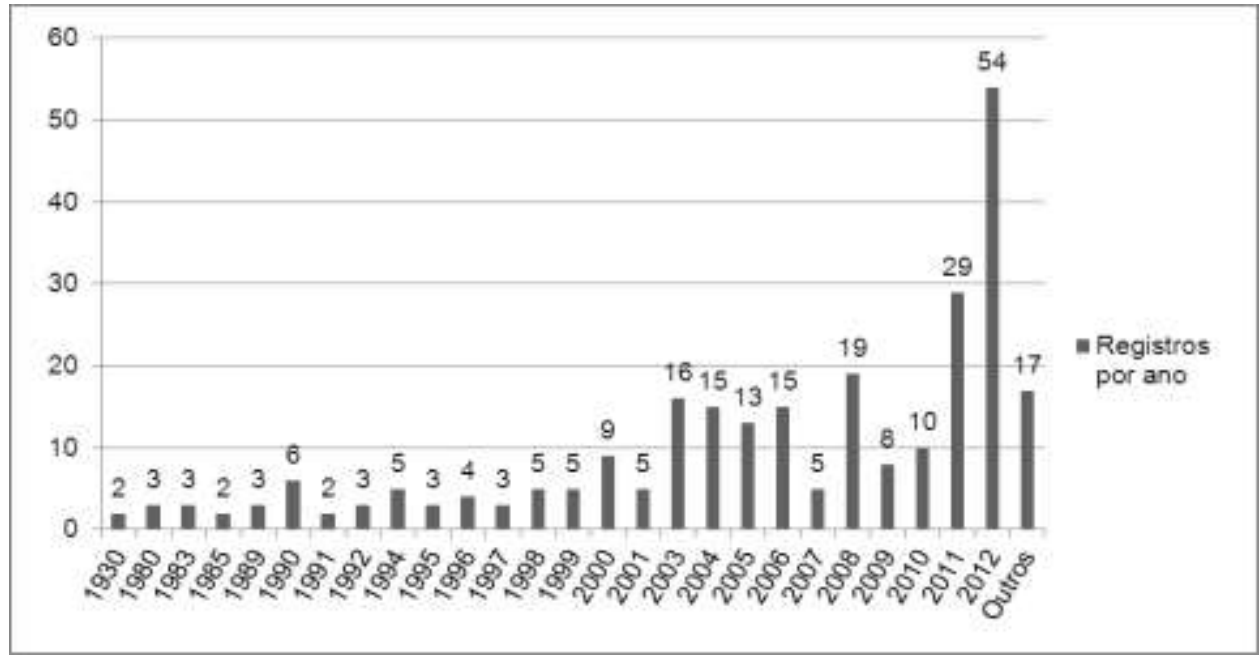

Fonte: os autores

Considerando-se que a pesquisa englobou publicações realizadas até 2012, percebe-se que o gráfico possui inclinação ascendente, sendo que, a partir do ano de 2003, foi identificada uma tendência de crescimento do número de publicações sobre o assunto. Conclui-se que o tema 
"Sistema de Gestão Ambiental" foi ganhando importância crescente no meio acadêmico ao longo dos últimos 10 anos.

- Para a palavra Hotel Industry, foram identificados 198 registros, distribuídos em base de dados.

Gráfico 4 - Distribuição dos registros que contém a palavra-chave "Hotel Industry" por base de dados

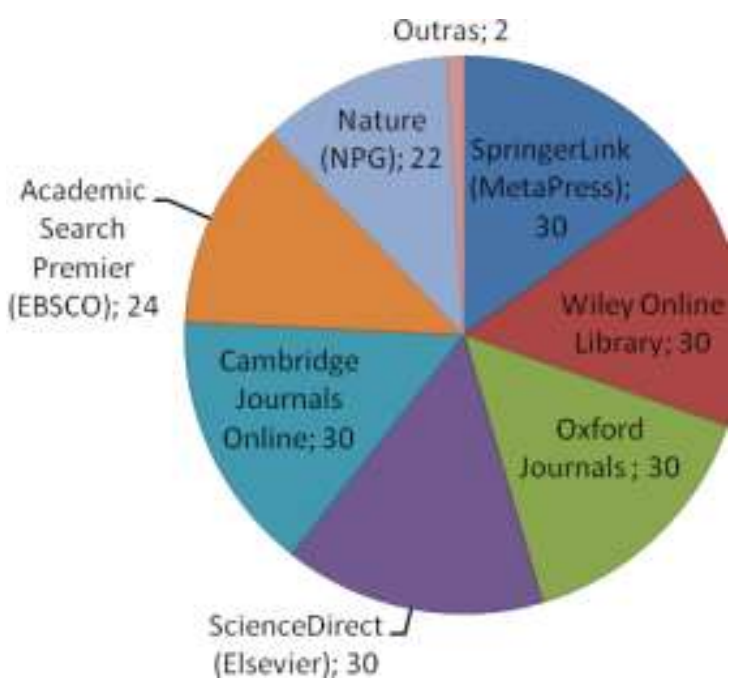

Fonte: os autores

- Para a palavra Sustainable Development, foram identificados 232 registros, que estão relacionados com diferentes assuntos (Gráfico 5). Cabe ressaltar que existem 201 outros assuntos que têm apenas um registro em cada um deles, corroborando os dados obtidos com a respectiva palavra-chave em português, "Desenvolvimento Sustentável".

Gráfico 5 - Distribuição dos registros que contêm a palavra-chave Sustainable development de acordo com assunto.

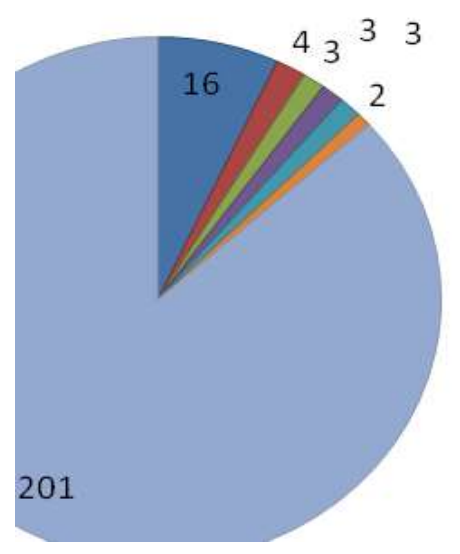

Earth and Environmental Science (16)

Humanities, Social Sciences and Law (4)

$\square$ Negóciose Economia(3)

Engenharia (3)

Biomedical and Life Sciences

$\square$ China (2)

Outros (201)

Fonte: os autores 
No Gráfico 5, observa-se a predominância da área Ciências da Terra e Ambientais, assim como apresentado no Gráfico 2, com o uso da palavra-chave Desenvolvimento Sustentável, o que representa o crescimento nacional e internacional de publicação nesta área.

\subsection{Pesquisa com as palavras-chave combinadas (em inglês)}

A dispersão apresentada no Gráfico 5 motivou realizar novas pesquisas para identificar efetivamente o número de produção científica relacionada ao tema.

- Para a combinação "EMS" e "Hotel Industry", foram identificados 147 registros distribuídos em 5 (cinco) bases de dados.

Gráfico 6 - Distribuição, por base de dados, dos registros que contém as palavras-chave "EMS" e "Hotel Industry" combinadas

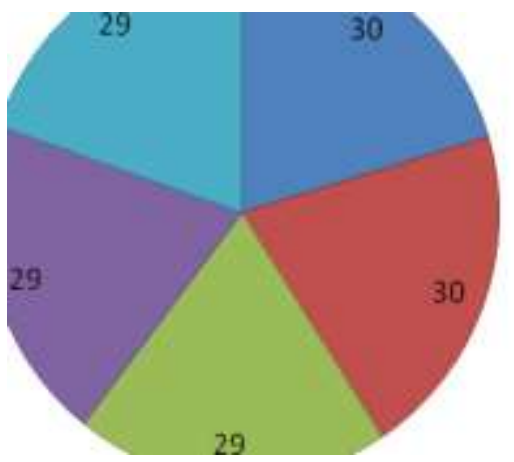

国ScienceDirect (Elsevier)

springerLink (MetaPress)

- Wiley Online Library

nature (NPG)

a Cambridge Journals Online

Fonte: os autores

A análise do Gráfico 6 resulta no nivelamento entre o número de artigos publicados nas bases de dados, o que pode representar uma tendência de crescimento consistente na produção científica com as palavras "Sistema de Gestão Ambiental" e "Indústria Hoteleira".

O Gráfico 7 evidencia o aumento da produção científica no tema, em especial a partir de 2006, que totalizou 88 artigos e representa 60\% em relação aos 147 artigos registrados. 
Gráfico 7 - Quantidade de registros por ano de publicação que contém as palavras-chave "EMS" e "Hotel Industry" combinadas

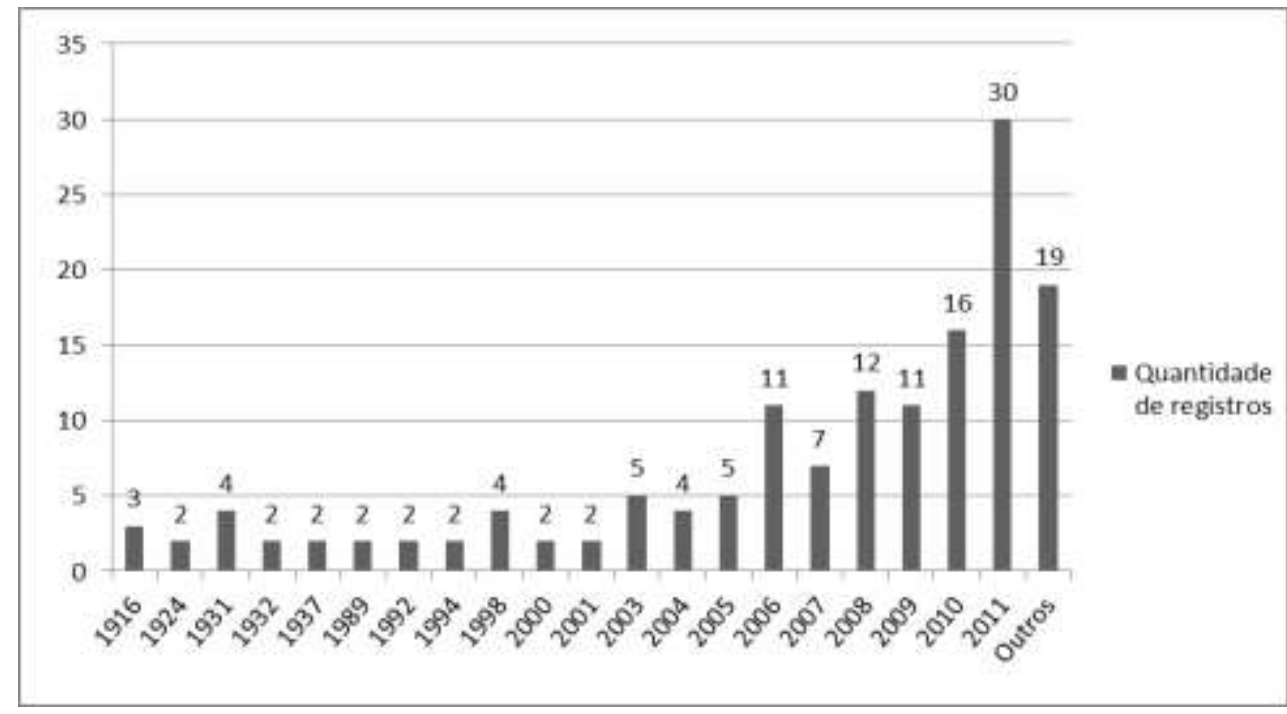

Fonte: os autores

A evolução das pesquisas sobre o tema reflete uma preocupação crescente da Indústria Hoteleira com relação à adequação de seus processos às novas exigências ambientais. A análise dos resumos (abstracts) dos oito artigos publicados entre 2006 e 2012 foi relevante para o refinamento da pesquisa. Em seguida, 27 artigos foram selecionados em função da correlação com o tema desta pesquisa, utilizando as palavras-chave: "Sistema de Gestão Ambiental” e "Indústria Hoteleira”. O Gráfico 8 representa a distribuição destes 27 artigos por ano.

Gráfico 8 - Quantidade de registros por ano de publicação após o primeiro refinamento manual

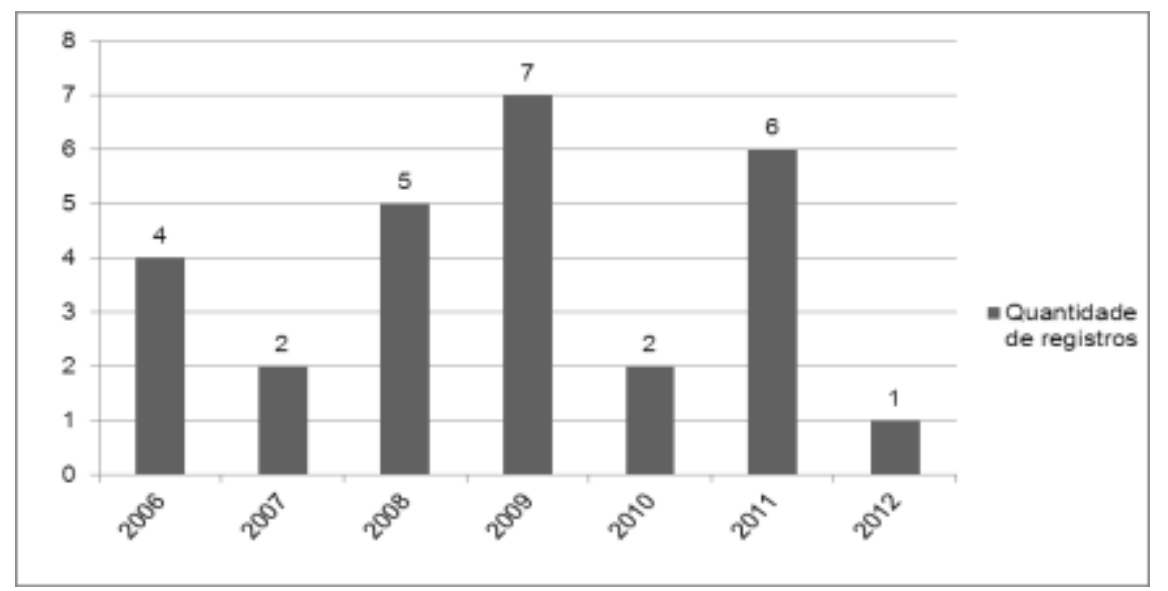

Fonte: os autores

\subsection{Diretrizes de gestão ambiental para atividade hoteleira no Brasil}

Para compor as diretrizes apresentadas neste tópico, foram selecionados os artigos mais relevantes, considerando o tema tratado. O Quadro 1 apresenta a descrição destes artigos que foram 
utilizados para a análise critica da pesquisa e para apontar diretrizes para implantação da gestão ambiental das atividades de hotelaria no Brasil.

Quadro 1 - Artigos mais relevantes (2006-2012)

\begin{tabular}{|c|c|c|}
\hline $\begin{array}{l}\text { Base de Dados } \\
\text { \& Autor(es) } \\
\end{array}$ & $\begin{array}{l}\text { Titulo do } \\
\text { Artigo } \\
\end{array}$ & Diretrizes para a Gestão Ambiental em Atividades de Hotelaria \\
\hline $\begin{array}{l}\text { Wiley Online } \\
\text { Library - } 2006 \\
\text { Autor: } \\
\text { Silvia Ayuso }\end{array}$ & $\begin{array}{l}\text { Adoption of } \\
\text { voluntary } \\
\text { environmental } \\
\text { tools for } \\
\text { sustainable } \\
\text { tourism: } \\
\text { analysing the } \\
\text { experience of } \\
\text { Spanish hotels }\end{array}$ & $\begin{array}{l}\text { Este artigo apresenta os resultados de pesquisa empírica realizada com } \\
\text { hotéis espanhóis que adotaram uma ou mais das ferramentas ambientais } \\
\text { existentes. Com base em uma exploração qualitativa das percepções e } \\
\text { experiências dos gerentes de hotéis aplicando estes instrumentos, o } \\
\text { entendimento geral do conceito de turismo sustentável é examinado, e a } \\
\text { aplicação prática de diferentes instrumentos ambientais voluntários é } \\
\text { analisada. }\end{array}$ \\
\hline $\begin{array}{l}\text { ScienceDirect } \\
\text { (Elsevier) - } 2006 \\
\text { Autor: } \\
\text { ERIC.S.W. Chan } \\
\text { País Estudo de } \\
\text { Caso: Gana }\end{array}$ & $\begin{array}{l}\text { Motivations for } \\
\text { ISO } 14001 \text { in } \\
\text { the hotel } \\
\text { industry }\end{array}$ & $\begin{array}{l}\text { Este estudo investiga as práticas de gestão ambiental entre diferentes } \\
\text { categorias de hotéis na Greater Accra Region (GAR) em Gana. A } \\
\text { literatura existente sobre as práticas de gestão ambiental em hotéis foi } \\
\text { utilizada como base teórica para o estudo. Com a utilização do método } \\
\text { de amostragem estratificada, obteve-se uma amostra de } 52 \text { gerentes de } \\
\text { hotéis de várias categorias na região, os quais responderam aos } \\
\text { questionários sobre o estudo. Um dos achados do estudo foi que, para os } \\
\text { hotéis com políticas ambientais, essas políticas eram orientadas para } \\
\text { alcançar ambientes seguros, limpos e saudáveis. }\end{array}$ \\
\hline $\begin{array}{l}\text { ScienceDirect } \\
\text { (Elsevier) - 2008 } \\
\text { Autor: } \\
\text { ERIC.S.W. Chan } \\
\text { País Estudo de } \\
\text { Caso: Líbia }\end{array}$ & $\begin{array}{l}\text { Barriers to } \\
\text { EMS in the } \\
\text { hotel industry }\end{array}$ & $\begin{array}{l}\text { Este artigo analisa questões relacionadas com o setor hoteleiro da Líbia, } \\
\text { incluindo a necessidade de fortalecer o setor privado, para combinar } \\
\text { educação / formação com as necessidades industriais, e para abordar as } \\
\text { dimensões cultural e religiosa que exacerbam a imagem da indústria. O } \\
\text { documento identifica uma abordagem de parceria entre governo, setores } \\
\text { da educação e da hotelaria, para tratar de questões de desenvolvimento } \\
\text { de recursos humanos através do planejamento da força de trabalho. }\end{array}$ \\
\hline $\begin{array}{l}\text { Cambridge Journals } \\
\text { Online - } 2008 \\
\text { Autores: } \\
\text { Hugh S. Gorman e } \\
\text { Samir A. Qadir } \\
\text { País Estudo de } \\
\text { Caso: Índia }\end{array}$ & $\begin{array}{l}\text { The use of ISO } \\
14001 \text { in India: } \\
\text { More than a } \\
\text { certificate on } \\
\text { the wall? }\end{array}$ & $\begin{array}{l}\text { Ao usar a Índia como um exemplo de caso, este artigo analisa os } \\
\text { benefícios e limitações da ISO } 14001 \text { na melhoria do desempenho } \\
\text { ambiental das empresas em países em desenvolvimento. No final, } \\
\text { concluiu-se que o valor da certificação ISO } 14001 \text { está intimamente } \\
\text { ligado à qualidade do processo de certificação, bem como à eficácia do } \\
\text { sistema local de regulamentação. Além disso, seu principal valor parece } \\
\text { estar nos efeitos positivos associados a um sistema de gestão ambiental } \\
\text { bem implementada, o que melhora a capacidade de uma empresa para } \\
\text { cumprir com as regulamentações ambientais consistentes e eficientes em } \\
\text { longo prazo. }\end{array}$ \\
\hline
\end{tabular}




\begin{tabular}{|c|c|c|}
\hline $\begin{array}{l}\text { Base de Dados } \\
\text { \& Autor(es) } \\
\end{array}$ & Titulo do Artigo & $\begin{array}{l}\text { Diretrizes para a Gestão Ambiental em Atividades de } \\
\text { Hotelaria }\end{array}$ \\
\hline $\begin{array}{l}\text { SciELO.ORG - } \mathbf{2 0 1 0} \\
\text { Autores: } \\
\text { André L. P. Freitas e } \\
\text { Georgia M. M. de } \\
\text { Almeida } \\
\text { País Estudo de Caso: } \\
\text { Brasil }\end{array}$ & $\begin{array}{l}\text { Avaliação do } \\
\text { nível de } \\
\text { consciência } \\
\text { ambiental em } \\
\text { meios de } \\
\text { hospedagem: uma } \\
\text { abordagem } \\
\text { exploratória }\end{array}$ & $\begin{array}{l}\text { Este artigo propõe uma abordagem exploratória para avaliar o } \\
\text { nível de consciência ambiental em meios de hospedagem, } \\
\text { segundo a percepção dos empresários e hóspedes. Um estudo foi } \\
\text { realizado com o objetivo de captar: (i) o perfil dos } \\
\text { estabelecimentos e dos hóspedes; (ii) o nível de consciência } \\
\text { ambiental do administrador/empresário e dos hóspedes; (iii) as } \\
\text { ações praticadas pelos estabelecimentos; e (iv) a postura dos } \\
\text { hóspedes em relação ao meio ambiente e à hospedagem. }\end{array}$ \\
\hline $\begin{array}{l}\text { ScienceDirect (Elsevier) - } \\
2011 \\
\text { Autor: } \\
\text { ERIC.S.W. Chan } \\
\text { País Estudo de Caso: } \\
\text { Hong Kong }\end{array}$ & $\begin{array}{l}\text { Implementing } \\
\text { Environmental } \\
\text { Management } \\
\text { Systems in Small- } \\
\text { and Medium- } \\
\text { Sized Hotels: } \\
\text { Obstacles }\end{array}$ & $\begin{array}{l}\text { Este estudo teve como objetivo identificar as barreiras para a } \\
\text { adoção e implementação de um SGA formal nas Pequenas e } \\
\text { Médias Empresas (PME) de Hong Kong. Análise fatorial } \\
\text { exploratória indicou que nove fatores podem dificultar a adoção } \\
\text { de tal sistema pela PME, cinco dos quais são únicos a esses } \\
\text { hotéis. Em ordem decrescente, são: (a) falta de um senso de } \\
\text { urgência (b) ambiguidade de padrões no SGA, (c) a falta de } \\
\text { pessoal qualificado, (d) orientações conflitantes e (e) suporte } \\
\text { inconsistente. }\end{array}$ \\
\hline $\begin{array}{l}\text { SpringerLink -2011 } \\
\text { Autor: } \\
\text { Joanna Oleskow-Szlapka } \\
\text { País Estudo de Caso: } \\
\text { Polônia }\end{array}$ & $\begin{array}{l}\text { Pro-ecological } \\
\text { Solutions Applied } \\
\text { in Hotels: } \\
\text { Examples }\end{array}$ & $\begin{array}{l}\text { Junto com a crescente preocupação das empresas e dos } \\
\text { consumidores sobre as questões ambientais, está o } \\
\text { desenvolvimento do turismo e um de seus ramos mais } \\
\text { importantes, que é a indústria hoteleira, para que caminhe para o } \\
\text { lado "verde" e implemente mais e mais soluções ambientalmente } \\
\text { amigáveis. Este estudo aborda padrões mundiais para hotéis } \\
\text { ecológicos e as soluções aplicadas na indústria hoteleira polonesa. } \\
\text { O objetivo é avaliar soluções aplicadas e sugerir algumas outras } \\
\text { oportunidades de tornar-se verde. }\end{array}$ \\
\hline $\begin{array}{l}\text { Disponível em: } \\
\text { http://www.proppi.uff.br/t } \\
\text { urismo/sites/default/files/s } \\
\text { istema_de_gestao_ambien } \\
\text { tal_no_segmento_hoteleir } \\
\text { o.pdf; Acessado em 05 de } \\
\text { maio de 2013, 21:48h. } \\
\text { Autores: Schenini, Pedro } \\
\text { Carlos; Lemos, Renato } \\
\text { Nunes; Silva, Fernando } \\
\text { Amorim da. }\end{array}$ & $\begin{array}{l}\text { Sistema de gestão } \\
\text { ambiental no } \\
\text { segmento } \\
\text { hoteleiro }\end{array}$ & $\begin{array}{l}\text { Entre os benefícios provenientes de um SGA para hotéis, } \\
\text { destacam-se: redução de geração de resíduos, redução do } \\
\text { consumo de água e energia; aumento da ecoeficiência; melhoria } \\
\text { dos processos; redução de custos; aumento do faturamento; } \\
\text { aumento da autonomia dos funcionários; retenção de hóspedes; } \\
\text { incremento da satisfação dos hóspedes; melhoria da imagem } \\
\text { hoteleira perante a sociedade. Para que um hotel consiga a } \\
\text { certificação da ISO 14001, é imprescindível que exista a } \\
\text { reorganização da empresa, conjugada com o comprometimento da } \\
\text { alta administração, a participação de todos os colaboradores, } \\
\text { profissionalismo, infraestrutura adequada, mão de obra } \\
\text { qualificada e a coordenação de todas as atividades propostas pela } \\
\text { ISO 14001. Com a disseminação da responsabilidade ambiental a } \\
\text { cada setor da organização, quando todos passam a ver as questões } \\
\text { ambientais sob a mesma ótica, soluções criativas começam a } \\
\text { surgir de toda a empresa. A certificação da norma ISO 14001, em } \\
\text { um hotel, depende, também, da comunidade, dos órgãos } \\
\text { governamentais, da própria estrutura do hotel, da capacidade de } \\
\text { investimento, da infraestrutura local e da característica do } \\
\text { estabelecimento. A visibilidade de um certificado perante as } \\
\text { exigências de certos mercados influenciam fortemente a decisão } \\
\text { das organizações. A conscientização ambiental para hotéis é um } \\
\text { processo global e de longo prazo e compete a cada empresa fazer } \\
\text { a sua parte. A ISO 14001 possui uma proposta ambiental racional, } \\
\text { como também de responsabilidade social, onde é }\end{array}$ \\
\hline \multirow[t]{2}{*}{$\begin{array}{l}\text { Base de Dados } \\
\text { \& Autor(es) }\end{array}$} & Titulo do Artigo & $\begin{array}{l}\text { Diretrizes para a Gestão Ambiental em Atividades de } \\
\text { Hotelaria }\end{array}$ \\
\hline & & possível reduzir o impacto ambiental e ao mesmo tempo pr \\
\hline
\end{tabular}




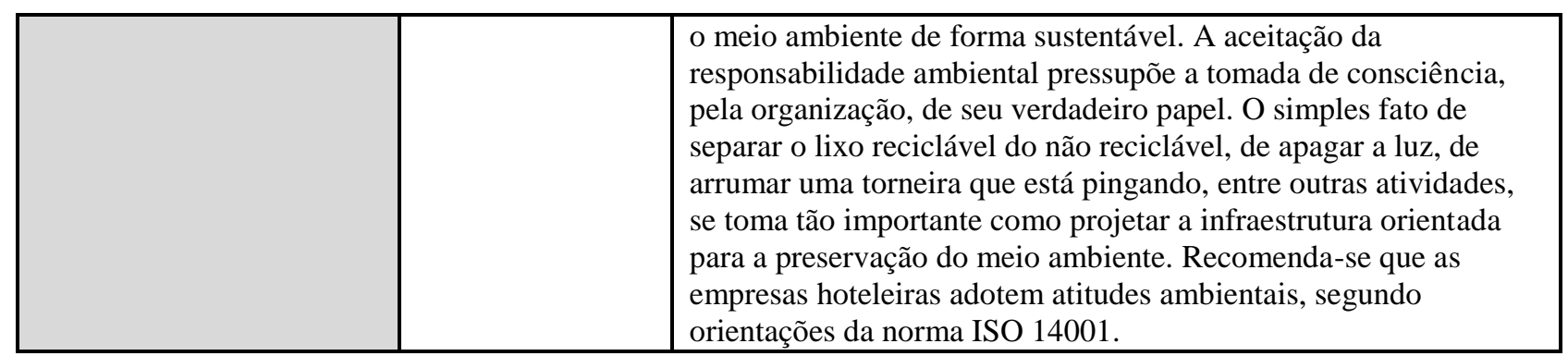

Fonte: os autores (2014)

O Quadro 1 evidencia uma tendência de relevância da gestão ambiental em atividades de hotelaria, no âmbito nacional quanto internacional. O conceito Desenvolvimento Sustentável é muito amplo, pois está relacionado com os diversos setores, o que torna complexa a implementação na Indústria Hoteleira, principalmente em função do grande percentual de empresas de pequeno porte. A produção científica aborda, preponderantemente, um dos aspectos da sustentabilidade: a responsabilidade ambiental e seu impacto nos resultados econômicos advindos de melhor competitividade no mercado.

A análise dos artigos selecionados pelo estudo bibliométrico evidencia algumas premissas sobre o tema:

- Em função das características diferenciadas dos empreendimentos hoteleiros, para adequar aos conceitos do desenvolvimento sustentável, é necessário adotar uma ou mais ferramenta ambiental (ISO 14001, Produção mais Limpa, Análise do Ciclo de Vida etc.), de preferência com baixo custo para implantação.

- Para os hotéis com políticas ambientais já implantadas, as práticas são orientadas para alcançar ambientes seguros, limpos e saudáveis.

- Existe a necessidade de firmar parcerias entre governo, setores da educação e da hotelaria, para tratar de questões de desenvolvimento de recursos humanos, a fim de promover uma cultura para a sustentabilidade nos empreendimentos hoteleiros.

- A implantação de um Sistema de Gestão Ambiental (exemplo: ISO 14001) melhora a capacidade da empresa hoteleira para cumprir com as regulamentações ambientais de forma consistente e eficiente em longo prazo.

- O desenvolvimento do turismo também está sofrendo pressão das partes interessadas para a implantação de um Turismo Sustentável, com empreendimentos hoteleiros adequados, bem como hábitos e padrões de vida e de consumo sustentáveis.

- A partir da revisão bibliográfica e do desenvolvimento de um SGA para a hotelaria, é possível constatar a viabilidade da aplicação da ISO 14001 no setor hoteleiro. Um sistema de gestão ambiental objetiva melhoria do desempenho ambiental da empresa, prevenção da poluição e o 
cumprimento da legislação ambiental aplicável. Trata-se de processo cíclico onde o sistema é revisto e avaliado de forma a identificar oportunidades de melhorias. Entre os benefícios provenientes de um SGA para hotéis, destacam-se: redução de geração de resíduos, redução do consumo de água e energia; aumento da ecoeficiência; melhoria nos processos; redução de custos de operação; aumento da receita; autonomia dos funcionários; fidelização de clientes; incremento da satisfação dos clientes; melhoria da imagem da hotelaria perante a sociedade.

- A implantação de SGA para hotéis não ocorre de forma imediata. Para que um hotel obtenha certificação ISO 14001, é imprescindível que exista como pré-requisito a reorganização da empresa, associada com o comprometimento da alta administração, a participação de todos os colaboradores, meritocracia, infraestrutura adequada, mão de obra qualificada e a coordenação de todas as atividades propostas pela ISO 14001. Com a disseminação da responsabilidade ambiental a cada área da organização, todos veem questões ambientais sob a mesma ótica e soluções inovadoras emergem na empresa.

- A certificação da norma ISO 14001 em hotel depende da comunidade, dos órgãos governamentais, da própria estrutura do hotel, da capacidade de investimento, da infraestrutura local e das características do hotel. A visibilidade de um certificado perante exigências dos mercados influencia fortemente a decisão das organizações.

A gestão ambiental em hotéis é processo global e de longo prazo. A ISO 14001 possui proposta ambiental racional. A ISO 26000 também oferece indicadores referenciais para alto desempenho em responsabilidade social. As organizações contemporâneas industriais e prestadoras de serviço buscam reduzir o impacto ambiental, agregar valor à sociedade e garantir retorno correto e justo aos seus investidores. O gerenciamento ambiental para hotéis é um tema recente e inovador. No entanto, tem promovido transformações significativas na consciência coletiva, aparecendo, assim, como fenômeno de singular importância no contexto da sustentabilidade.

\section{Considerações finais}

Esta conclusão expõe as respostas às questões de pesquisa: Quais os desafios que a hotelaria tende a enfrentar para tornar-se ambientalmente responsável? Como deverão essas empresas se comportar doravante para que possam se sustentar no mercado e atender à demanda crescente de turistas mais exigentes, do ponto de vista ambiental e de serviços especializados? Quais as diretrizes de gestão para a hotelaria ambiental?

Desenvolvem-se, no decorrer do artigo, argumentos para consolidar o objetivo da pesquisa, que é a análise da relação entre a indústria hoteleira e o desenvolvimento sustentável no Brasil e no mundo, e definir diretrizes para a implantação da gestão ambiental em hotelaria. 
O estudo bibliométrico permitiu a identificação dos trabalhos disponíveis nas principais bases de dados do Portal Periódico CAPES, os mais antigos, os mais recentes e os mais relevantes relacionados à abordagem do tema de maneira globalizada, Isso leva a considerar que a pesquisa teve êxito mesmo frente à dificuldade de enquadrar o tema em relação a sua tradução em português.

Com base nos resultados, foi possível comprovar o enfoque diferenciado dado ao termo Desenvolvimento Sustentável e à combinação do termo Desenvolvimento Sustentável e Indústria Hoteleira. Enfoque este não mais baseado no conceito arcaico do desenvolvimento do Turismo de forma pontual, mas sim, de um Turismo Sustentável, onde as partes interessadas devem ser parceiras para atender à expectativa dos clientes e promover o desenvolvimento sustentável do setor.

Ao se levar em consideração que a legislação interfere diretamente na sustentabilidade, face ao seu poder de controle, é fundamental a participação das partes interessadas, em especial o governo, pois o mercado tem foco na competência e na meritocracia. A definição desse caminho será dada pelo próprio empreendedor, através da capacitação profissional e da melhoria dos equipamentos e ferramentas de suas empresas, para poderem sobreviver dentro de uma perspectiva de competitividade cada vez mais acirrada.

Com base na fundamentação teórica, atualmente o turista tem um perfil mais exigente, consciente e ético. Por este motivo, se faz necessário o desenvolvimento de uma atividade turística mais responsável, planejada e com a participação, responsabilidade e contribuição de todos os envolvidos no turismo como sistema.

O crescimento da produção científica sobre o tema representa a maior problemática apresentada nesta pesquisa, o que significa que o mercado está demandando por uma indústria hoteleira mais sustentável. Os gestores dos meios de hospedagem devem, agora, se unir e se qualificar em busca desse objetivo.

Diante do exposto, a conclusão aponta para a necessidade de uma reflexão mais cuidadosa sobre o turismo, que evidencie, além de suas possibilidades, o seu controle e limite, onde, só a partir do reconhecimento do turismo como atividade econômica relevante que requer planejamento participativo, análise, pesquisa e informações consistentes, será possível a sua inclusão na perspectiva da sustentabilidade.

Contudo, deve ser considerado que, para se alcançar tal objetivo, mais do que "certificar-se" é necessário que essas empresas abracem uma nova consciência de suas responsabilidades, acreditando e apostando em estratégias sustentáveis, onde os métodos adotados sejam mantidos, por meio de controle, manutenção e correção, quando necessário, para se praticar um turismo mais responsável. 
Como sugestão de novas pesquisas, propõe-se que estas sejam promovidas para comparação entre o desempenho, internacional e o nacional, da hotelaria em desenvolvimento sustentável e, particularmente, em gestão ambiental.

\section{Abstract}

This article analyzes the activities related to tourism "sustainable". Centers focus on definitions of literature on the Hotel Industry and Sustainable Development under the focus on the environmental aspect. The research method is deductive and is classified as applied research concerning the nature, exploratory, about the objectives and theoretical-conceptual, and the method. Conducts bibliometric analysis to identify the academic activities related to hospitality and environmental management. The article identifies what has been produced and published knowledge generated by the scientific community related to the theme, and analyze its main trends. For this, we constructed a tree of keywords in order to search publications. We observed an increase of the recent publications on the topic, identifies the use of environmental management system in hotel activity contributes to the effective management and acts as a factor fostering competitiveness.

Key-words: environmental management systems (EMS); hotel industry; sustainable development.

\section{Referências}

AMAZONAS, E. et al. Estudo Raio X da Hotelaria Brasileira, As Redes Hoteleiras do Brasil. 2006. Disponível em: http://www.raioxhotelaria.com.br/vitrinehotel.php>. Acesso em: mai. 2007.

ASSOCIAÇÃO BRASILEIRA DA INDÚSTRIA HOTELEIRA- ABIH; Ministério do Turismo; Serviço Brasileiro de Apoio às Pequenas Empresas - SEBRAE. Manual de Conduta Hoteleira. Disponível em: http://www.abih.com.br. Acesso em: dez. 2009

AYUSO, S. Adoption of voluntary environmental tools for sustainable tourism: analyzing the experience of Spanish hotels. Wiley Online Library. 2006.

BRASIL. Ministério do Meio Ambiente. Lei n. ${ }^{\circ}$ 11.771, de 17 de setembro de 2008. Dispõe sobre a Política Nacional de Turismo (PNT).

CHAN,E.S.W. Implementing Environmental Management Systems in Small - and Medium-Sized Hotels: Obstacles. Journal of Hospitality \& Tourism research, v. 35, n.1, p.3-23, fev. 2011. crossref

.Barriers to EMS in the hotel industry. International Journal of Hospitality Management, v. 27, n. 2, p.187198, jun. 2008. crossref

Motivations for ISO 14001 in the hotel industry. Tourism Management, v.27, n.3, p. 481-492, jun. 2006. crossref

FREITAS, A. P.; DE ALMEIDA, G. M. M. Avaliação do nível de consciência ambiental em meios de hospedagem: Uma abordagem exploratória. Revista Sociedade \& Natureza, v. 22, n. 2, p. 405-417, ago. 2010. 
GIL, A.C. Como elaborar Projetos de pesquisa. São Paulo: Atlas, 1996.

GONÇALVES, L. C.; Gestão Ambiental em Meios de Hospedagem. 1ª reimpr. São Paulo: Aleph, 2004.

GORMAN,H.S; QADIR,S.A. The use of ISO 14001 in India: More than a certificate on the wall ? Cambridge Journals Online, 2008

KRIPPENDORF, J.; Sociologia do turismo: para uma nova compreensão do lazer e das viagens. São Paulo: Aleph, 2001.

MINISTÉRIO DO TURISMO, Brasil. 2011. Site oficial:

http://turismo.gov.br/turismo/programa_acoes/qualificação_equipamentos.Acesso em: 01 dez. 2011.

. Gabinete do Ministro do Ministério do Turismo. Portaria n ${ }^{\circ}$ 100, de 16 de junho de 2011 do. Brasil, 2011

MORAES, A. A Certificação Ambiental dos Meios de Hospedagem: uma análise das motivações para a aplicação da certificação ambiental nos meios de hospedagem de Balneário de Camboriú. Turydes, Santa Catarina. v. 2., n. 6, nov./dez. 2009.

NAKANO, D. Metodologia de Pesquisa em Engenharia de Produção e Gestão de Operações. Paulo Augusto Cauchick Miguel (Org.). Rio de Janeiro: Elsevier, 2010.

NASCIMENTO, H.; SILVA, V.; Turismo Pós-moderno: dilemas e perspectivas para uma gestão sustentável. Holos, Ano 25, v. 3, p. 103-116, 2009.

OLESKOW-SZLAPKA, Joanna. Pro-ecological Solutions Applied in Hotels: Examples. SpringerLink, 2011.

NETTO, A. P. Filosofia do Turismo: teoria e epistemologia. São Paulo: Aleph, 2005.

QUELHAS, O.L.G.; ALLEDI, C. Sustentabilidade das organizações brasileiras. Niterói: ABEPRO, 2006.

RUSCHMANN, D. M. Turismo e planejamento sustentável: a proteção ao meio Ambiente. Campinas, SP: Papirus, 1997.

SWARBROOKE, J. Turismo Sustentável: conceitos e impacto ambiental. Vol. 1. São Paulo: Aleph, 2000.

SACHS, I. Ecodesenvolvimento: crescer sem destruir. São Paulo: Vértice, 1996.

SCHENINI, P.C; LEMOS, R.N; Silva, F.A; Sistema de Gestão Ambiental no Segmento Hoteleiro, 2005. Disponível em: http://www.proppi.uff.br/turismo/sites/default/files/sistema_de_gestao_ambiental_no_segmento_hoteleiro.pdf. Acesso em: 05 maio 2013

TURRIONI, J. B., MELlO, C. H. Metodologia de Pesquisa em Engenharia de Produção. São Paulo: CampusABEPRO, 2011

\section{Dados dos autores}

Nome completo: Marcos Antônio Bezerra Sereno, M. Sc.

Filiação Institucional: Universidade Federal Fluminense - UFF

Departamento: Laboratório de Tecnologia, Gestão de Negócios e Meio Ambiente - LATEC

Função ou cargo ocupado: Mestre em Sistema de Gestão 
Endereço completo para correspondência: Rua Passo da Pátria,156, Sala 329-A - Bloco E - Escola de Engenharia - São Domingos - Cep: 24210-240 - Niterói - Brasil

Telefone: +5521 2629-5546

e-mail: marcos.sereno@uol.com.br

Nome completo: Osvaldo Luiz Gonçalves Quelhas, D. Sc.

Filiação Institucional: Universidade Federal Fluminense- UFF

Departamento: Laboratório de Tecnologia, Gestão de Negócios e Meio Ambiente - LATEC

Função ou cargo ocupado: Professor Associado - Coordenador do Doutorado em Sistemas de Gestão Sustentáveis

Endereço completo para correspondência: Rua Passo da Pátria,156, Sala 329-A - Bloco E - Escola de Engenharia - São Domingos - Cep: 24210-240 - Niterói - Brasil

Telefone: $+55212629-5520$

e-mail: quelhas@latec.uff.br

Nome completo: Sérgio Luiz Braga França, D. SC.

Filiação Institucional: Universidade Federal Fluminense- UFF

Departamento: Laboratório de Tecnologia, Gestão de Negócios e Meio Ambiente - LATEC

Função ou cargo ocupado: Coordenador do Mestrado Profissional em Sistemas de Gestão

Endereço completo para correspondência: Rua Passo da Pátria,156, Sala 329-A - Bloco E - Escola de Engenharia - São Domingos - Cep: 24210-240 - Niterói - Brasil

Telefone: +5521 2629-5546

e-mail: sfranca@latec.uff.br

Nome completo: Marcelo Jasmim Meiriño, D.Sc.

Filiação Institucional: Universidade Federal Fluminense- UFF

Departamento: Laboratório de Tecnologia, Gestão de Negócios e Meio Ambiente - LATEC

Função ou cargo ocupado: Coordenador no Núcleo de Inovação e Tecnologia para a

Sustentabilidade (NITS/UFF)

Endereço completo para correspondência: Rua Passo da Pátria,156, Sala 329-A - Bloco E - Escola de Engenharia - São Domingos - Cep: 24210-240 - Niterói - Brasil

Telefone: $+55212629-5546$

e-mail: marcelo@latec.uff.br

Submetido em: 18/07/2014

Aceito em: 18/12/2014 